\title{
FACTORS AFFECTING BLOOD LOSS DURING OPEN REDUCTION AND INTERNAL FIXATION (ORIF) OF ISOLATED CLOSED FEMORAL FRACTURES AT MULAGO HOSPITAL
}

C.K. KINYANJUI, MBChB (Moi), MMed (ORTH) MUK, P.O.Box 19407-00100, Nairobi, Kenya, Email:ckiarie2002ke@yahoo.com

\section{ABSTRACT}

Background: In open reduction and internal fixation (ORIF) of femur, blood loss is characterised by slow continuous haemorrhage characteristic of muscle stripping, subperiosteal dissection and osteotomy. Blood loss may however be minimised by meticulous surgical technique which is perfected by training and experience.

Objective: To assess the amount of blood loss during ORIF of isolated closed femoral fractures in Mulago Hospital.

Setting : Mulago National Hospital ,Uganda.

Design: This was a cross-sectional analytical study.

Methods: Purposive sampling was used. These were patients in Ward 7 of Mulago Hospital. The allowable blood loss was calculated using the haemodilution method. Blood loss was calculated by weighing dry and blood soaked gauze swabs. The amount of intravenous fluids was recorded. The patient was monitored for pulse rate, blood pressure and urine output. Data processing and analysis was done by use of SPSS-10 package.

Results: The mean blood loss intraoperatively was $930 \mathrm{mls}$. Long duration of surgery was associated with more blood loss. Older fractures bled more than fresh fractures. Use of diathermy was associated with significantly less blood loss.

Conclusion: Fractures should be fixed early and use of diathermy should be encouraged to minimise blood loss.

\section{INTRODUCTION}

The use of diathermy and positioning of the patient in a way that encourages free venous drainage at the operative site (1) is a practical and inexpensive way of minimising blood loss during surgery. The operative site should be a little above the level of the heart (1). Good anaesthetic technique reduces episodes of hypertension and tachycardia due to sympathetic over activity by ensuring adequate anaesthesia and analgesia (1). Regional anesthesia is also associated with less blood loss $(1,2)$. Haemodilution has been shown to be a cost effective way of decreasing blood loss (3). Other methods of reducing blood loss include the use of collagen pads, thrombin powders and fibrin glue (3). Vasopressin, gamma amino caproic acid and aprotinin have also been used to decrease blood loss (3).

\section{MATERIALS AND METHODS}

During the operation, gauze swabs were weighed in their dry state while in their sterile packs. Blood soaked swabs were weighed as soon as they were discarded into a plastic paper bag. The suction bottle was weighed before and after use. This is because the calibration on the suction bottle is widely spaced and hence difficult to quantify small differences in blood loss by visual observation. Any gauze swabs not used were subtracted from the initial dry weight. It has been shown that $1 \mathrm{ml}$ of blood weighs approximately $1 \mathrm{~g}$.
This was the difference in weight of the used dry and wet swabs. Volume of irrigation fluids was noted and subtracted from the measured blood loss. Blood loss onto the floor was estimated and added to that of the wet swabs and suction bottle to get the total blood loss. Blood on the floor was estimated at the ratio of one litre of blood spreads over an area of 1 square meter (2).large blood clots were weighed together with the wet gauze swabs. Gauze mops were spread around the surgical area on the surgical drapes to absorb any blood spillage.

\section{RESULTS}

A total of 40 patients were included in this study. All successfully underwent ORIF of an isolated closed femoral fracture.

Demographic characteristics: Most patients (37.5\%) in the study sample were in the age group between 2636 years. The least $(5 \%)$ were in the age group between 56-65 years (Figure 1). The figures inside the graph represent actual number of patients.

Thirty two $(80 \%)$ of the patients in the study were males (Figure 2). The numbers in brackets represent actual number patient numbers.

Most $(67.5 \%)$ patients lost $1000 \mathrm{mls}$ or less of blood intraoperativel y (Figure 3)

The numbers inside the graph represent actual number of patients 
Figure 1

Age distribution of cases

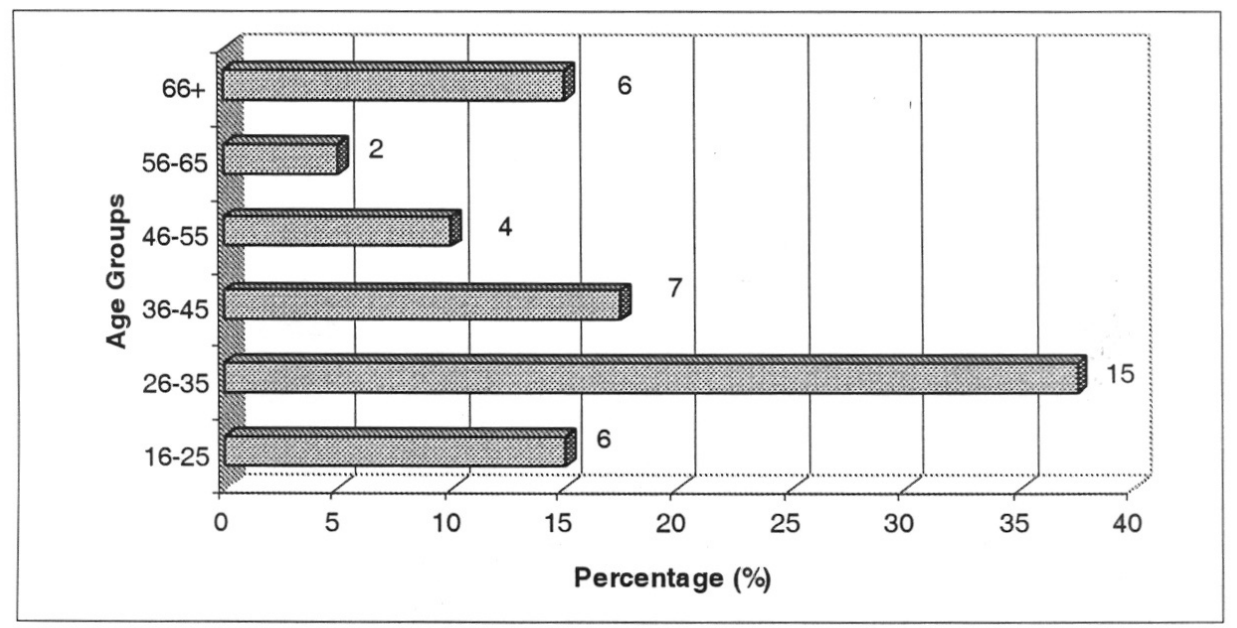

Figure 2

Sex distribution of cases

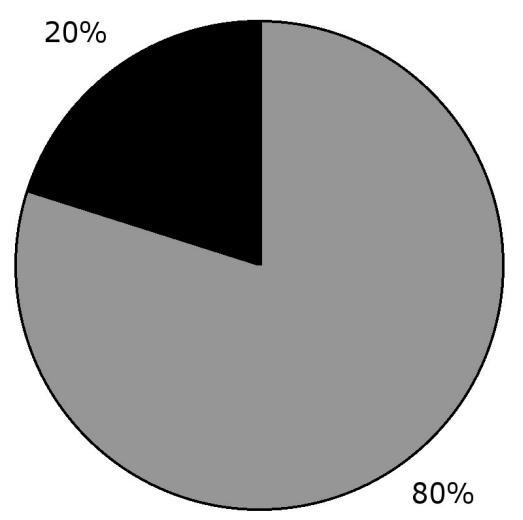

Most $(1285 \mathrm{mls})$ intraoperative blood loss was in the age group of 36-45 years followed by 26-35 years $(1130 \mathrm{mls})$. Increasing blood loss with age was not statistically significant. ( $p$-value $=0.192$ ). The age group between $26-45$ years sustained a high blood loss. This was associated with fixation of shaft fractures with SIGN-nail in which there was a lot of soft tissue dissection (Table 1).

Despite the fact that some old fractures had less blood loss than fresh fractures, in general, the older fractures incurred more blood loss intraoperatively and this relationship was statistically significant (P-value $=0.009$ ) (Table 2).

The use of diathermy resulted in less blood loss intraoperatively (mean $=672 \mathrm{mls}$ ) and this relationship was statistically significant ( $p$-value $=0.016$ ) (Table 3 ). Total blood loss was increased with intraoperative time and this relationship was statistically significant $(p$-value $=0.000)($ Table 4$)$.

Figure 3

Intra-operative total blood loss

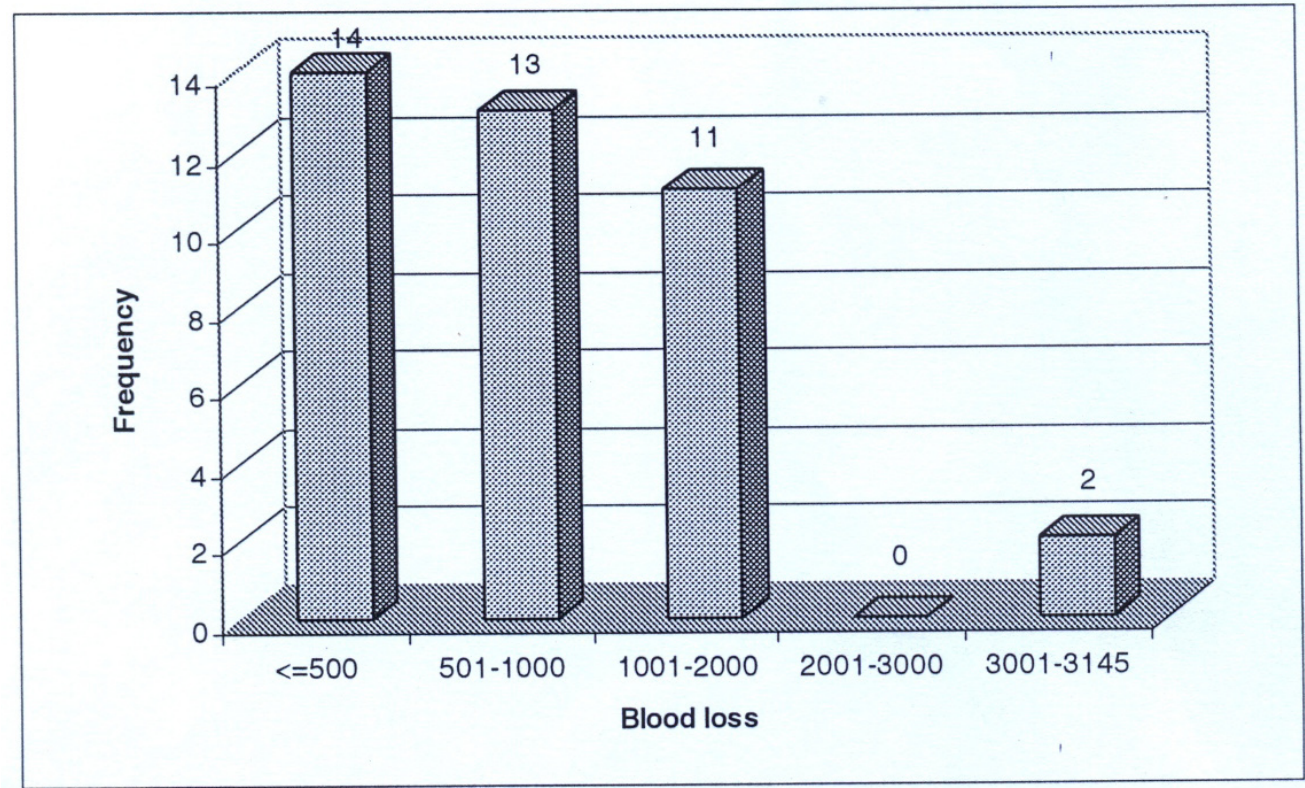


East African Orthopaedic Journal

Table 1

Total blood loss intra-operatively by age group

\begin{tabular}{llllll}
\hline Age group (years) & Number & Mean blood loss & Std deviation & df & Sig \\
\hline $16-25$ & 6 & 625.83 & 280.19 & & \\
$26-35$ & 15 & 1130.27 & 721 & \\
$36-45$ & 7 & 1285.00 & 948.12 & & \\
$46-55$ & 4 & 443.75 & 204.51 & 5 & 0.192 \\
$56-65$ & 2 & 495.00 & 254.56 & 585.21 & \\
$66+$ & 6 & 789.17 & 688.13 & \\
\hline Total & 40 & 930.10 & & \\
\hline
\end{tabular}

Table 2

Total blood loss intra-operatively by age of fracture

\begin{tabular}{llllll}
\hline Timing from injury in weeks & Number & Mean blood loss & Std deviation & Df & Sig. \\
\hline 2 & 6 & 2200.0 & 28.868 & 24 & 0.009 \\
3 & 5 & 2735.0 & 277.173 & & \\
4 & 2 & 841.457 & 127.279 & \\
5 & 4 & 1108.33 & 841.457 & \\
6 & 2 & 2250.75 & 655.445 & \\
9 & 5 & 1520.0 & 1139.57 & \\
11 & 6 & 3080.00 & 318.199 & \\
14 & 2 & 865.00 & - & \\
16 & 1 & 1120.00 & - & \\
21 & 1 & 3145.00 & - & \\
26 & 1 & 1120.00 & - & \\
30 & 1 & 1880.00 & - & \\
51 & 1 & 1 & 315.00 & \\
156 & 40 & 930.00 & - & \\
\hline
\end{tabular}

Table 3

Total blood loss by use of diathermy

\begin{tabular}{llllll}
\hline Use of diathermy & Number & Mean blood loss & Std deviation & df & Sig. \\
\hline Yes & 20 & 672.00 & 375.498 & 1 & 0.016 \\
No & 20 & 1188.20 & 831.103 & & \\
\hline Total & 40 & 930.10 & 688.132 & & \\
\hline
\end{tabular}

Table 4

Total blood loss intra-operatively versus total duration of surgery

\begin{tabular}{|c|c|c|c|c|c|}
\hline Duration of surgery & Number & Mean blood loss & Std deviation & df & Sig. \\
\hline 1.0 & 7 & 598.57 & 412.176 & & \\
\hline 1.5 & 13 & 613.46 & 344.495 & & \\
\hline 2.0 & 15 & 1039.27 & 477.915 & 5 & 0.000 \\
\hline 2.5 & 2 & 672.50 & 672.50 & & \\
\hline 3.0 & 2 & 2512.50 & 2512.50 & & \\
\hline 3.5 & 1 & 3080.00 & 737.50 & & \\
\hline Total & 40 & 930.10 & 688.132 & & \\
\hline
\end{tabular}

\section{DISCUSSION}

The mean intra-operative blood loss was $930 \mathrm{mls}$ with a minimum of $315 \mathrm{mls}$ and a maximum of $3145 \mathrm{mls}$ in one patient (Table 2). A different study found a mean blood loss of $1277 \mathrm{mls}$ (4). The mode of fixation of fractures was by the open method, which is the same method that was used for ORIF in this study.

Blood loss increased linearly with age up to 45 years, after which, there was a decrease in blood loss (Table 1). This may be explained by the fact that most patients in the younger age group underwent K-nailing or SIGN-nailing. SIGN-nailing was associated with a larger amount of blood loss (mean $=1451.13 \mathrm{mls}$ ). Most patients older than 55 years underwent Austine Moore hemiarthroplasty, which had a considerably lower blood loss (mean $=741.50 \mathrm{mls}$ ) in this study. Thus the expected increasing blood loss with age was not statistically significant in this study ( $(p-$ value $=0.192)$ (Table 1). A different study found the highest blood loss with DHS to be $300 \mathrm{mls}$; their longest operation time was $90 \mathrm{~min}$ (5). That was in a European country 
and the use of cell savers or haemostatic agents such as fibrin glue was not specified. Thus, the results on blood loss may not really be comparable. In this study DHS incurred a blood loss of $642.5 \mathrm{mls}$; the mean duration of surgery however was $135 \mathrm{~min}$. Women had a high blood loss (Mean=1087.50mls) as compared to men (Mean $=890.75 \mathrm{mls}$ ). This was however, not statistically significant $(P$-value $=0.477$ ) as women comprised only $20 \%$ (Figure 2 ) of the patient population in this study.

It was noted that fixation of comminuted fractures incurred higher (mean=1972.5mls) blood loss than the simple fractures (6). This may be due to extensive soft tissue injury and increased surgical time in trying to obtain anatomical reduction in such fractures (6). However, this observation was not statistically significant ( $p$-value $=0.88$ ), because only two fractures were comminuted in the study sample of 40 patients.

Patients with mid third fractures sustained a mean blood loss of $1405.82 \mathrm{mls}$ (Table 3 ). This was attributed to fixation using SIGN -nail, which had a mean operation time of 2.063 hours. There was extensive opening of soft tissues with SIGN-nail, which may account for the high blood loss. However, blood loss based on the location of fracture did not attain statistical significance ( $p$-value $=0.058)$.

There was much less blood loss in the operations done by consultants together with residents (Mean=606.11 mls) as compared to cases done by registrars (Mean $=1038.59 \mathrm{mls}$ ). This may be attributable to less surgical time, less soft tissue damage and more experience by the consultants. However, this relationship did not achieve statistical significance ( $p$-value $=0.256$ ) as there were only nine patients operated by consultants with residents. The distribution of different procedures between the two groups was also not uniform thus making it difficult to compare the two outcomes.

Blood loss increased gradually with increasing time from the date of injury. This was statistically significant ( $p$-value $=0.009$ ) (Table 2 ). This is due to longer operation time in such fractures which sometimes have partially malunited or contain a lot of fibrous tissue; the new bone at the fracture site is also more vascular thus more bleeding (6). Anatomical reduction also takes time because soft tissues usually have contracted in old fractures (6).

There was significantly less blood loss intra-operatively with diathermy (mean $=672 \mathrm{mls}$ ) as opposed to $1188 \mathrm{mls}$ without use of diathermy (2). This relationshipwasstatistically significant $(p$-value $=0.016$ ) (Table 3). This is because diathermy coagulates most of the small blood vessels responsible for continuous oozing during surgery $(2,7)$. A different study found that electrocautery decreases incision time, blood loss, early post operative pain and analgesia requirements (7). Blood loss increased significantly with duration of surgery16 (p-value $<0.001$ ) (Table 4). This is attributable to continuous oozing from muscle, periosteum and intramedullary canal (6). Angled blade plating for subtrochanteric fractures incurred the highest amount of blood loss (mean $=1581 \mathrm{mls}$ ), followed by SIGN-Nailing (Mean=1451mls). The difference in blood loss among the different procedures was however, not statistically significant ( $p$-value $=0.079$ ). The two cases where tourniquet was used in the supracondylar region incurred a lower blood loss intraoperatively (mean $=312 \mathrm{mls}$ ) as opposed to $962 \mathrm{mls}$ in higher fractures where tourniquet is not used. This was not statistically significant ( $p$-value $=0.197$ ) as there were only two cases in which tourniquet was used. Post operatively though the two supracondylar fractures had the highest post operative blood loss indicating less aggressiveness in tying small blood vessels when tourniquet was released.

There was less blood loss with use of spinal anaesthesia (mean $=650 \mathrm{mls}$ ) as opposed to general anaesthesia $($ mean $=944 \mathrm{mls})$. This is in tandem with what has been found by other studies and is attributable to the regional hypotensive effects of spinal anaesthesia caused by sympathetic nerve blockage hence less oozing at the operation site $(1,6,24,31)$. Hypotensive anaesthesia has been found to decrease blood loss by $40 \%$ (3). This relationship was however not significant ( $p$-value $=0.562$ ) because there were only two cases done under spinal anaesthesia.

\section{CONCLUSION}

The mean blood loss during ORIF of femur was $910.10 \mathrm{mls}$. Fractures should be fixed early and use of diathermy should be encouraged to minimise blood loss.

\section{REFERENCES}

1. Yves, O. and Claude, L. Non pharmacological approaches to decrease surgical bloodloss. Can. J. Anesth. 2003; 50:519-525.

2. Jean, C. and Antony, C., (Eds). WHO Blood Transfusion Safety.The clinical use of blood in medicine, obstetrics, paediatrics, surgery and anesthesia. Trauma and Burns (WHO). 2001; 4:1-426.

3. Mark, L. and William, H. Current concepts reviewBlood transfusions in orthopaedic operations. J. Bone Joint Surg. 1996; 78: 1260-1271.

4. Lawrence, R., Benjamin, B. and Rappaport, W. Blood loss in patients with isolated femoral fractures. $J$. Orthopaedic Trauma. 1992; 6:175-179.

5. Bolhofner H. and Brett, R. Results of intertrochanteric femur fracture treated with a 135-degree sliding screw with a two hole side plate. Journal of Orthopaedic Trauma. 1999;13:5-8.

6. Phillips, R.and Keneth,D.,(Eds).Femoral shaft fractures. Skeletal trauma. (2) 50:1927-2023.

7. Kearns, S. and Connoly, E. Randomised clinical trial of diathermy versus scalpel incision. Brit. J. Surg. 2001; 88: 41-44.

8. Jerrold,H.and Levy,P.Novel Pharmacologicapproaches to reduce bleeding. Canadian J. Anesthesia. 2003; 50: 526-530. 